\title{
Late Jurassic to early Early Cretaceous tectonic nature on the NE Asian continental margin: Constraints from Mesozoic accretionary complexes
}

\author{
YU LI ${ }^{12}$, WEN-LIANG XU ${ }^{2}$, FENG WANG ${ }^{2}$ \\ 'State Key Laboratory of Lithospheric Evolution, Institute of Geology and Geophysics, \\ Chinese Academy of Sciences, Beijing, China; liyu19900821@126.com \\ ${ }^{2}$ College of Earth Sciences, Jilin University, Changchun,China
}

The tectonic nature between the continental margin of NE Asia and the Paleo-Pacific plate during the Late Jurassic to early Early Cretaceous remains debated. In this paper, we discuss the formation and emplacement history of the Mesozoic accretionary complexes (AC) in the NE Asian continental margin based on their rock associations, provenance and metamorphic-deformation history, with the aim of further constraining the tectonic nature between the NE Asian continental margin and the Paleo-Pacific plate during the Late Jurassic to early Early Cretaceous.

The Mesozoic AC at the continental margin of the NE Asia can be subdivided into two stages, i.e., Jurassic and Early Cretaceous. The earliest timing of the Mesozoic AC arrival at the trench occurred at $\sim 195 \mathrm{Ma}$. Combined with the early Mesozoic igneous rock association along the continental margin of the NE Asia, it is suggested that the initial subduction of the Paleo-Pacific oceanic plate beneath the Eurasia took place in the Early Jurassic. Additionally, the Jurassic AC in Japan suffered from a regional high-P/T metamorphism with the peak age of $160 \mathrm{Ma}$, which could be related to the subduction-collision of the seamounts with the Eurasia at the trench. The age spectrum and Hf isotope compositions indicate that these Jurassic clastic sediments mainly sourced from the South China Block, whereas the early Early Cretaceous clatics sourced from the eastern CAOB. The strike-slip tectonic nature between NE Asian continental margin and the Paleo-Pacific Plate during the Late Jurassic to early Early Cretaceous, which could be related to small angle of oblique subduction of the PaleoPacific plate beneath the Eurasia. Westward subduction of the Paleo-Pacific Plate beneath the Eurasia occurred during the late Early Cretaceous, leading to the final emplacement of the Raohe and Khabarovsk AC at 137-130 Ma, and the formation of the Early Cretaceous AC in the Russuan Far East and Japan.

This research was financially supported by the National Natural Science Foundation of China (Grants 91858211, 41688103, and 41902054). 